\title{
Facilitating father engagement: The role of Family Relationship Centres
}

\section{RICHARD J FLETCHER*1}

Family Action Centre, Faculty of Health, The University of Newcastle, New South Wales

\section{AMY L VISSER}

Family Action Centre, Faculty of Health, The University of Newcastle, New South Wales

\section{ABSTRACT}

The default position of the Family Law Amendment (Shared Parental Responsibility) Act 2006 is that children are able to spend substantial and meaningful amounts of time with each parent following separation, The legislation also requires (with some exceptions) that from July 2007, former partners make a bona fide attempt to resolve parenting disputes through family dispute resolution processes. To this end, the establishment of 65 Family Relationship Centres has been approved and funded. In this paper, we argue that fathers and mothers attending the new Centres for dispute resolution may typically have different approaches to mediation and counselling. Furthermore, some individuals' or service providers' beliefs and stereotypes about men's emotions may inhibit fathers' engagement and reduce the effectiveness of the services being provided. Although difficult to measure, 'father engagement' in dispute resolution processes can be taken to include engendering trust and setting goals with the father, while simultaneously balancing the inclusion of the mother. Instruments to gauge fathers' degree of alliance with the mother as a co-parent, and investment in the child, may provide useful outcome measures of the process of father engagement. Professional competencies identified in the cross-cultural literature, such as self-reflective capacity, offer a starting point for equipping practitioners to engage with fathers to ensure that Family Relationship Centres meet their goal of improved outcomes for separating families.

Key words: fathers; mediation; relationship conflict; counselling; father engagement

$\mathrm{T}$ he Family Law Amendment (Shared Parental Responsibility) Act 2006 signals a fundamental shift in the approach to parenting disputes following family dissolution, from a legally-informed and ultimately court-based adversarial system to a dispute resolution and conflict management approach using an Australia-wide network of community-based support

* Correspondence to: Richard Fletcher, Engaging Fathers Research Program, Family Action Centre, Faculty of Health, The University of Newcastle, NSW 2308, Australia; tel: (02) 49 21640; fax: (02) 49218686.

1. This research was funded by an Attorney General's Department Grant in partnership with Interrelate Family Centres. 
services. Two important principles incorporated into the 2006 Family Law reforms are a default position of mothers and fathers sharing the care in ways that permit ongoing meaningful relationships with the children and, in normal circumstances, the resolution of disputes about this position, using dispute resolution processes.

The reforms signalled a new recognition of the importance of fathers in children's development and in family well-being. By emphasising a connection between the child and both parents as a fundamental right of the child, the legislation challenged earlier common practices that tended to see one parent (usually the mother) as the key parent after separation, while according 'visiting rights' to the other parent. In addition, by requiring parents, under normal circumstances, to negotiate over their child's future contact and activities with them (eg by completing a parenting plan for example), the legislation aims to set in place a process that can support any future adjustments that may be necessary. At the same time, the deleterious effect of violent and abusive behaviour, an area in which men are over represented as perpetrators (Scott \& Crooks 2004) is also recognised by the legislation. Former partners are not required to attempt to negotiate parenting arrangements where allegations of violence or abuse have been made.

In emphasising both parents' roles in child development, the Australian legislation echoes principles laid down by the United Nations Convention on the Rights of Children. It also follows the increasing weight of social science evidence (eg that a father's relationship with family members, not simply his presence or absence, is a key determinants of a child's well-being.

The successful implementation of the new approach hinges on the provision of support through community-based services to assist separating families to make workable arrangements for their children without having to go to court. For couples in the midst of conflict, key services will provide child focused or child inclusive dispute resolution sessions (see Moloney \& McIn- tosh 2004), child-focused group parenting programs (see McIntosh \& Moloney 2006) and family counselling, all designed to engage both fathers and mothers.

A major difficulty in facilitating the negotiation of parenting arrangements for children, either in lead up to or in the aftermath of separation, is that discussions not infrequently take place in an emotionally-charged environment (Emery, Sbarra \& Grover 2005; Foster et al 2005; Lamb, Sternberg \& Thompson 1997). Painful issues of disappointment, jealousy, indignation or even rage may, in obvious ways, limit parents' willingness or ability to compromise and come to agreements (McIntosh \& Deacon-Wood 2003). Even if communication between the parties is relatively cordial, the ending of any relationship in which children are involved will undoubtedly lead to the experience of some level of regret and probably grief and is very likely to involve painful emotions (Katz 2007).

The affective burden carried by parents seeking assistance from mediation, counselling and related services presents a challenge for staff since, most commonly, their task is simultaneously to acknowledge the difficulties faced by each parent, while focusing on the goal of developing satisfactory child-focused parenting arrangements (Emery et al 2005; Holmes 2006; Sourdin, Fisher $\&$ Moloney 2004). In the case of relationships in which violence is or has been a factor, the possible risks for women entering mediation or counselling with male partners has received considerable attention (Field 2004; Keys Young 1996; Kirkwood 2006). Since the mid 1990s in Australia, training and education of mediators and counsellors around questions of violence has been frequently advocated. Particular attention has been paid to the gendered presentations of violence by the clients themselves, to ensure that women are not disadvantaged in their use of services (eg Clemants \& Gross 2007; Zaher 1998). What has not been considered, however, is how gender might influence other non violence-related interactions when parents present to 
family mediation and counselling. Specifically, the possibility that services might overlook gender differences between mothers and fathers in the emotionally-laden processes of mediation and counselling has not been seriously addressed.

An example of the gendered nature of separation and divorce is the way in which men and women arrive at the decision to separate. Hewitt, Western and Baxter (2006) examined Australian data on over 9,000 first marriages to answer 'Whose decision was it to finally separate?' While both men and women agreed that wives initiated the process of separation more often than husbands, their estimates of the difference varied: $27 \%$ of husbands believed they initiated the separation and $35 \%$ believed that their wives initiated the decision (38\% believed that it was a joint decision); whereas wives believed that they initiated the separation in $58 \%$ of cases compared to $17 \%$ for their husbands. Similar results were reported by Wolcott and Hughes (1999) from a random national telephone survey of 650 divorced Australians: $64 \%$ of women compared with $21 \%$ of men indicated that it was mostly themselves who had made the decision to separate. How does the decision (or perceived decision) to separate impact on the question of preparedness and subsequent responses? Bickerdike and Littlefield (2000) suggested that the non-initiator is more likely to experience reactive hostility as well as lingering attachment to the former spouse, factors which may impact on the non-initiator's willingness or capacity to engage in counselling or dispute resolution.

In addition, differences in the approaches of men and women to negotiations may not simply be the result of who initiates the separation. Cross and Madson (1997), suggested that the high proportion of women who initiate divorce may be due to women being more cognisant of relationship difficulties than men, combined with a heightened sense of dissatisfaction or distress when these problems cannot be resolved. Gilligan (1977) first proposed a coherent argument for recognising sex differences in moral reasoning.
She suggested that while men might opt for abstract rules to decide complex dilemmas, women would be more likely to address responsibilities and relationships between individuals in their reasoning. This explanation is consistent with the well-documented differences in U.S. populations between women's and men's selfconcept. Cross and Madsen (1997) found that women are more likely to describe themselves in terms of relatedness to others, while men are more likely to describe themselves in terms of independence from others.

There is also some evidence that fathers and mothers (men and women) have different styles of communication when they come to negotiate relationship difficulties. For example, in a sample of Israeli couples, men have been found to more often use arguments that are unemotional and based on fact, logic and law, whereas women may use arguments that are more emotional and more often about the emotions that they are experiencing, such as pain, rejection or insult (Pines, Gat $\&$ Tal 2002). Men may also exhibit more unemotional communication styles in situations where there is a risk of rejection or emotional pain (Vogel et al 2003).

\section{Mediation, counselling and the 2006 reforms}

Family Relationship Centres, a centrepiece of the 2006 reforms, offer or are linked through referrals, to a range of services including family dispute resolution and counselling. While there are accepted differences between goal-focused negotiations such as mediation that take place within a clear time frame, and more exploratory, healingoriented consultations such as counselling or psychotherapy, the processes have also been found to overlap (Smyth \& Moloney 2003). Mothers and fathers seeking mediation are invariably in conflict. Whilst mediation seeks to address cognitive processes (identify options, consider alternatives etc) the willingness of parties to enter into serious negotiation also depends on managing the emo- 
tions involved in the dispute (Jones \& Bodkter 2001).

Recent developments in family dispute resolution involving children have emphasised the necessity to effectively address the acrimony involved (Hewlett 2007) and have argued that mediators have a 'responsibility for influencing the psychology of family re-structure' (McIntosh \& Long 2006: 12). It is therefore proposed to examine the consequences of gender differences in the use of dispute resolution and counselling services in order to explicate the ways that gender may be taken into account in offering assistance to mothers and fathers in the midst of separation or divorce negotiations over their children. These ways include the measuring of father engagement, conceptualising practitioner competencies, and taking into account the cultural context.

\section{GENDER DIFFERENCES IN APPROACHING DISPUTE RESOLUTION AND RELATIONSHIP COUNSELLING}

A recent study recounts the following situation:

Daniel is a middle-aged account executive who says that he has come to therapy because he is tired of all the arguments. His wife Jennifer, who is a teacher, states that there is little intimacy in their relationship and hopes that this can improve. Daniel admits that Jennifer threatened to leave the marriage if he didn't come to therapy. He suggests that the real problem is that his wife is too emotional. Crying quietly, Jennifer acknowledges that there is something wrong with her because she can't seem to control her emotions on those frequent occasions when they disagree. Hearing this, Daniel states that perhaps the best course would be for his wife to continue in therapy alone. (Symonds \& Horvath 2004: 443)

This scenario is typical in couple therapy, and captures some aspects of male-female differences when taking action to address relationship diffi- culties. Although not all men can be expected to behave differently from all women, there is consistent evidence of significant differences in men's and women's approach to seeking assistance when their personal well-being is under threat. See Galdas, Cheater and Marshall (2005) for a review. Men are generally less likely to access or take part in counselling or relationship assistance services, have lower rates of successful engagement with practitioners and are thought to require different styles of engagement than women (Addis \& Mahalik 2003; Aoun, Palmer \& Newby 1998; Baum 2004; Brooks 1998; Robertson \& Fitzgerald 1992). This is particularly true in the case of men who adhere to male identity values that emphasise independence and eschew emotional expression (Berger et al 2005; McCarthy \& Holliday 2004). Additionally, men's and women's coping styles within the context of grief or depression are reported to be dissimilar in many respects (Baum 2006; Brownhill et al 2005; Moynihan 1998). As Rickwood and Braithwaite (1994: 570) noted:

Norms of appropriate masculinity discourage expression and sharing of emotion. The Australian culture, in particular, has been described as a 'hard' culture, especially for men, who are expected to be tough, suppress their emotion, and avoid feminine qualities such as compassion.

The reluctance of men to engage with counselling processes is thought to be due to a variety of factors, including a limited awareness of emotion, an inability to express emotion, or a negative perception of help-seeking behaviour (particularly on matters of an emotional nature), as 'feminine' or 'suggesting vulnerability' (Addis \& Mahalik 2003; Baum 2004; Brownhill et al 2003; Ciarrochi 2001; Wong \& Rochlen 2005). Based on a review of coping mechanisms in the event of relationship loss, Stroebe, Stroebe and Schut (2001) found that men tend to use coping strategies that are problem-based, whereas women are more likely use strategies that are emotion- 
based. Also, where women are more likely to think and talk about their emotions as they experience them, men are more likely to actively avoid or distract themselves from such thoughts. In some instances (particularly in the case of depression), this avoidance can lead to anti-social or risk-taking behaviour in men (Brownhill et al 2005).

Methods currently employed by service providers may be more conducive to engaging with women than with men in that they require a degree of self-awareness, problem awareness and ability to discuss personal issues freely and openly. These tasks are likely to be more difficult for men who have socialised male gender role norms (Levant 1998; Robertson \& Fitzgerald 1992). More appropriate methods of engagement for fathers may involve either tailoring methods of communication to suit men, or conducting sessions in ways that help men feel less constrained by the traditional roles in which they tend to view themselves (Addis \& Mahalik 2003).

Put succinctly:

If counselling does not require men to set aside their sense of independence, their comfort with goals, tasks, and activities, or their preference of developing an understanding of a situation, then the idea of seeking help may be more appealing.

(Robertson, 2001, cited in McCarthy \& Holliday, 2004: 26)

The use of such methods, however, requires practitioners to be knowledgeable about gender differences and their associated stereotypes and committed to developing and utilising strategies and skills to engage both men and women.

In view of the importance of emotional factors in counselling, emotional stereotyping of males is likely to reduce practitioners' effectiveness (Heesacker \& Bradley 1997; Heesacker et al 1999). The Beliefs About Men's Emotions Scale (BAME) was developed to measure beliefs about men's typical emotional capacities and expressions (Heesacker et al 1999). Respondents completing the scale are asked to rate their agreement with statements such as 'Men don't express their emotions very much' and 'Men are afraid of their feelings'. In the 1999 study, psychology students were tested to assess if higher scores on the scale were associated with differential judgements regarding fault in heterosexual relationship conflict. Participants were required to watch a video tape of a relationship conflict and then completed the BAME scale and answer three open-ended questions assessing blame for the conflict. Those reporting greater stereotypical beliefs about men's emotions were more likely to blame the man for the relationship conflict, suggesting that a counsellor's stereotypical beliefs about fathers' abilities may influence their approach to assisting couples seeking help with dispute resolution.

Service providers may also fail to include fathers in the process resolving family disruption if they hold stereotypical beliefs regarding fathers' tendency to abuse children or lack of competence in providing for children's emotional needs. The Fitting Fathers into Families Report (Russell et al 1999) surveyed Australian service providers and professionals on their perceptions of fathers' influence on children and their perceptions of the key barriers to men becoming involved as parents and utilising services. Both male and female service providers agreed that mothers and fathers should share the responsibilities for bringing up children and, in general, assumed that fathers are committed to their role of fathering. However, the survey also found that over half the female staff and $34 \%$ of male staff believed that up to one in four $(24 \%)$ of fathers physically abuse their children. In a qualitative study, Hand (2006: 76) also found that mothers believed that 'men could not be trusted with the emotional aspects of parenting and running a household, lacking the patience and interest in small children required', perhaps highlighting the need for practitioners to be aware of a potential in themselves to underestimate the competence of a father when this is covertly or overtly implied by a mother. 


\section{MeAsuring father engagement}

The term 'engagement' is frequently utilised within the literature describing the helping relationship across health, welfare, education and counselling fields (Addington, Francey \& Morrison 2006; Brady \& Scully 2005; Coatsworth at al 2001). In general, it is used to define a positive relationship between a service or a practitioner and an individual accessing the service, whereby this relationship facilitates the meeting of the specific expectations of that individual (Dearing et al 2005). In the context of counselling practice, engagement appears to be somewhat of an elusive concept and measures of engagement are varied, ranging from counts of attendance at a service, to scales quantifying a client's trust or alliance with the practitioner (Martin, Garske \& Davis 2000). In some cases, engagement is measured against the service components as a whole. For example, engagement may be measured within the context of continued attendance at voluntary programs (Connors et al 1997) or the attendance of specific family members in a treatment (Coatsworth et al 2001). For this review, however, the focus is on the interactions occurring between individuals in a particular setting, that is, professionals in the role of counsellors or dispute resolution practitioners interacting with parents who are experiencing relationship difficulties. The measurement of engagement in such settings is valuable not only for examining effective practice but for clarifying and elaborating our understanding of 'engagement' and for describing the competencies required to fully include fathers in processes designed to resolve conflicts over parenting arrangements for dependant children.

The psychotherapy literature examining the effectiveness of different treatment modalities has consistently reported that treatment type is less significant than the quality of the relationship between the therapist and client. The underlying quality of the therapeutic process has been characterised in various ways, but most commonly as an 'alliance' between the therapist and client comprising collaboration in the task of therapy and an affective relationship between the two. In an influential paper, Bordin (1979) outlined a psychodynamic-based concept of the alliance with three dimensions: collaboration in undertaking the therapy in terms of goal setting, an affective bond between therapist and client and agreement on the appropriateness of the tasks involved. Bordin did not suggest that equal attention to all three dimensions was required at every stage of therapy, nor did he claim that alliance alone was sufficient for change. What his concept of the therapeutic alliance did offer, however, was a potentially pan theoretical conceptualisation of the therapeutic process that could be measured. Subsequent work by Horvath and Greenberg (1989) utilising this tripartite concept has generated a self-report measure - the Working Alliance Inventory (WAI) - consisting of 36 items with 12 items in each of the subscales. Examples of items reflecting the three dimension of the alliance are: 'The therapist and I trust one another' (bonding); 'The goals of these sessions are important to me' (goal setting); and, 'The things that the therapist is asking me to do don't make sense' (tasks - negatively scored).

The WAI offers both a possible measure of success in father engagement and an aid to conceptualising the elements which make up a counselling or mediation process inclusive of fathers. Father engagement will be more likely when the practitioner manages to create a relationship that is positive in tone and 'connects' with the perspective of the father, when the tasks (such as negotiating holiday arrangements) appear appropriate and the goal of meeting to address the family's arrangements is made acceptable to the father. A practitioner who is competent to engage with fathers in a family dispute would be expected to be knowledgeable about fathers' possible or even likely preconceptions of counselling or mediation and be aware of his possible discomfort with direct emotional expression and preference for practical, solution-focused tasks. Additional markers of competency would include a commitment to finding ways to form a positive 
bond with the father and the skills to accomplish this in the context of family disputation.

Although the WAI has been utilised in studies of helping relationships in a variety of settings and a meta analysis found acceptable rates of prediction for positive therapy outcome, the scale is limited to assessments of the dyad of client and practitioner. The need for a broader application has prompted the development of a couple version of the WAI to incorporate the balance required between the practitioners' (therapists') alliances with each member of a couple (Symonds 1999). Symonds and Horvath (2004) used a marital satisfaction scale to assess the impact of differing alliances between husband and wife and therapist with couples receiving therapy sessions. The scores for each of the three alliances - self, partner and couple - were aggregated to derive a rating of the alliance for each male and female client. The therapist also completed a scale to rate his or her alliance with each client and with the couple. The results, although preliminary, suggest that in couple sessions a positive rating of the alliance by clients predicts a positive outcome only when the couples' ratings agree. By contrast, the therapists' ratings of the alliance had little value in predicting post-treatment marital satisfaction. The authors posit the need for the therapist to balance the 'allegiance' between the couple with the alliances each client develops with the therapist.

In the context of divorce or separation, the complexity of the emotionally charged interactions involving multiple and competing perspectives requires successful practitioners to develop a high level of skill described by Holmes (2006: 117 ) as developing 'a depth of both affective and cognitive understanding of each case in-themoment, while concurrently engaging in selfevaluation and self-management'. The ability of the practitioner to facilitate similar levels of alliances with each person in the couple (or the perception of similar levels) is an additional requirement for practitioners forging an alliance with the father in family disputation work. See
Shay and Maltas (1998) for a detailed description of balancing alliances in couple counselling.

However, the goals of family relationship services are broader than achieving father or father and mother satisfaction; they include the development of sustainable parenting arrangements involving both mothers and fathers which are in the best interests of the child (Attorney-General's Department 2007). Outcome measures for evaluating successful father engagement in dispute resolution with families (separated or not) must ultimately include measures of family functioning and child well-being in the period following contact with support services.

While longitudinal studies using validated measures of family well-being will be required to test the ultimate success of dispute resolution (eg proxy measures of parents' ability to keep the well-being of their children in mind can sharpen our understanding of effective father engagement. The concept of 'parenting alliance', rooted in psychodynamic and systems theories (but not directly related to the WAI), describes those aspects of the couple relationship that are specifically concerned with parenthood and child rearing. A sound parenting alliance obtains if each parent is invested in the child, values the other parent's involvement with the child, respects the parenting judgements of the other parent and desires to communicate with the other parent (Weissman \& Cohen 1985). A Parenting Alliance Index (PAI) has been developed from this conceptual base and tested on 512 parents (191 fathers). The PAI correlated significantly in the expected direction with established measures of parenting and with target child's positive adjustment and social competence (Abidin \& Brunner 1995).

McBride and Rane (1998) examined the links between parenting alliance and fathers' involvement in child care of pre-schoolers. They found that fathers' perceptions of spouses' confidence in their (the father's) parenting, mothers' emotional appraisal of their spouses' parenting and shared parenting philosophy significantly predicted fathers' involvement. While preliminary, 
this evidence suggests that effective father engagement during dispute resolution could be linked to measures of the well-being of the child to fulfil the central objectives of Family Relationship Centres (McIntosh \& Long 2006). What remains to be described are the competencies required of practitioners to successfully engage with fathers, while maintaining engagement with mothers and respectfully challenging both parents to remain focused on children's needs.

\section{CONCEPTUALISING PRACTITIONER COMPETENCIES FOR FATHER- ENGAGEMENT}

McCarthy and Holliday (2004) have recently argued that sensitivity towards the needs of male clients in a counselling setting could be assessed in a similar fashion to that of the Multicultural Counselling Competencies adopted by the American Counselling Association. That is, they propose that traditional male values may form the basis of a male gender culture, steeped in qualities synonymous with socialised male norms, such as limiting the expression of emotion, reliance on self, autonomy and aggressiveness and that counsellors should adapt their practice to better address male clients' needs. The conception of male culture is not to be confused with cultures of minority, or sub-cultures within male identity such as ethnicity. Nor does it imply that all male needs can be homogenised. Rather, the authors suggested that male clients' reluctance to seek counselling assistance and indifference to standard counselling techniques, when viewed as 'cultural' factors, behoves the practitioners to reflect on their stereotypes and beliefs about men, educate themselves about male culture(s) and find techniques that suit men in need. As Liu (2005: $685)$ proposed 'men are socialised in a specific culture, with values, norms, customs, and expectations, to which men must adhere. Therefore, working effectively with men means an awareness of masculine cultural values and the clinician's understanding of his/her own assumptions and biases about men.
Unfortunately, while the psychology literature provides examples of techniques and strategies utilised by individual therapists and counsellors working with male clients, the field lacks an evidence base regarding effective practice with men, and no evaluations of training programs to assist practitioners to become 'culturally competent' with male clients have been reported. The suggestions available to counsellors, such as using the word 'workshop' in session description instead of 'counselling', emphasising problemsolving or introducing innovative ways of labelling and identifying emotions (Baum 2004; Robertson \& Fitzgerald 1992; Wong \& Rochlen 2005), amount to little more than a list of 'hints' or 'practice tips'. Nevertheless, the existing literature on cross-cultural (multicultural) competencies can provide some important conceptual clarification in the development of effective father-engagement practice in family disputation settings.

\section{Cultural COMPETENCY}

Competencies are commonly categorised into attitudes and beliefs, knowledge and required skills (Rodolfa et al 2005). Evaluations of cultural competency training have found that practitioners' changes in knowledge of diverse groups is ineffective in predicting practice change, and studies of ethnically diverse professionals find that ethnic group membership does not reliably predict cultural competence (Betancourt 2003; Jackson 2007; Kumas-Tan et al 2007). As well, because within-group variation is high, the tendency to generalise from limited personal contact with members of a client group can inhibit effective engagement so that simply being exposed to members of the client group may not increase competence; practitioners may simply repeat mistaken approaches (Reimann et al 2004). Applying this evidence to fathers suggests that knowledge about fathers, although important, may not translate into culturally competent practice. Male practitioners (who may be fathers) and female practitioners (who have experience of male family 
members and friends) may not be effective in engaging fathers.

Self-reflection, the ability to reflect on one's own beliefs and attitudes, has been identified as a key competence by the National Health and Medical Research Council (NHMRC) guide for cultural competency in health (National Health and Medical Research Council 2006). Thus, unhelpful beliefs about fathers (eg the belief that fathers [men] are 'afraid of their feelings') may be addressed through self-awareness and a willingness to assess the counsellor's own bias toward men. Self-reflection has also been considered a fundamental competence for family mediators (Sourdin et al 2004).

Cross-cultural research has also suggested an important skill in dealing with clients of other cultures is to exercise judgement in applying group characteristics to an individual. While the dangers of stereotyping - incorrectly attributing group characteristics to an individual - are widely recognised, the opposite mistake can also occur: ignoring cultural group characteristics that may be affecting that individual' (Sue 1998: 446). An important skill in work with fathers is the ability to recognise when male characteristics should be considered and allowances made and when individual characteristics should be emphasised.

The literature on effective health interventions for culturally diverse populations also points out that cultural competency can be viewed across four levels: systemic - including collecting demographic and service usage data; organisational including resource allocation and development of culturally inclusive policies; professional - including training opportunities at undergraduate and postgraduate level and staff development; and individual self-reflection and communication skills (National Health and Medical Research Council 2005). In fact, each of these levels has been identified in services' current efforts to include fathers (Fletcher 2004).

Finally, the cross-cultural literature also casts cultural competence as an ongoing process in which the practitioner 'continuously strives to achieve the ability to effectively work within the cultural context of an individual, family, or community from a diverse cultural/ethnic background' (Campinha-Bacote, Yahle \& Lagenkamp 1996: 59).

The Australian Community Services and Health Industry Skills Council is in the process of developing competencies for Vocational Graduate Diplomas of Relationship Work and of Dispute Resolution (Community Services \& Health Industry Skills Council 2007). The draft documents include optional units Work with Men, Engage fathers into family based programs and Working with separated fathers setting out performance indicators such as 'Assist fathers to understand their roles and impact as fathers in their children/s lives' and listing skill areas such as 'Critically reflect own practice in relation to father inclusive practices'. It remains to be seen whether optional units within a certificate framework will be sufficient preparation for effectively engaging with fathers in families, and it is also unclear how undergraduate and professional education will adapt to the need for father-engagement competencies.

\section{CONCLUSIONS}

In the case of family dissolution the best interests of the child require that, as far as possible, parents put aside their inter-parental conflict and purposefully negotiate arrangements which take account of the interests and optimal development of their children. Family Relationship Centres have been set up to foster this process where parents cannot agree. However, differences in men and women's emotional expression and preferred negotiating style, coupled with the possibility of gender stereotyping by practitioners, may pose difficulties in effectively engaging fathers in the dispute resolution process. Measures of engagement with clients in psychotherapy can provide direction in assessing father engagement; the cross-cultural counselling literature offers a starting point for identifying the father-engagement competencies needed by dispute resolution prac- 
titioners and counsellors. If the ambitious goals of the recent amendments to the Family Law Act are to be achieved, the development of a comprehensive framework for professional competencies in father engagement will be required.

\section{References}

Abidin R and Brunner J (1995) Development of a Parenting Alliance Inventory. Journal of Clinical Child Psychology 24: 31-40.

Addington J Francey SM and Morrison AP (eds) (2006) Working with People at High Risk of Developing Psychosis: A Treatment Handbook. John Wiley and Sons, Chichester, West Sussex.

Addis M and Mahalik J (2003) Men, masculinity, and the contexts of help seeking. American Psychologist 58: 5-14.

Aoun S, Palmer M and Newby R (1998) Gender issues in psychosocial morbidity in general practice. Australian Journal of Social Issues 33: 335-53.

Attorney-General's Department (2007) Family Relationships Online: Helping Families Build Better Relationships. Available at: http://www.family relationships.gov.au/ (accessed 3 September 2007).

Australian Government (2007) Family Relationships Online: Helping Families Build Better Relationships. Available at: http://www.familyrelation ships.gov.au/ (accessed 13 February 2008).

Baum N (2004) Help divorced men mourn losses. American Journal of Psychotherapy 58: 174-85.

Baum N (2006) Postdivorce paternal disengagement: Failed mourning and role fusion. Journal of Marital and Family Therapy 32: 101-114.

Berger JM, Levant RF, McMillan KK, Kelleher W and Sellers A (2005) Impact of gender role conflict, traditional masculinity ideology, alexithymia, and age on men's attitudes toward psychological help seeking. Psychology of Men and Masculinity 6: 73-8.

Betancourt JR (2003) Cross-cultural medical education: Conceptual approaches and frameworks for evaluation. Academic Medicine 78: 560-69.

Bickerdike AJ and Littlefield L (2000) Divorce adjustment and mediation: Theoretically grounded process research. Mediation Quarterly 18: 181-201.

Bordin ES (1979) The generalisability of the psychoanalytic concept of the Working Alliance. Psychotherapy: Theory, Research and Practice 16: 252-260.

Brady L and Scully A (2005) Engagement: Inclusive Classroom Management. Pearson Education, Sydney.

Brinig MF and Allen DW (2000) 'These boots are made for walking': Why most divorce filers are women. American Law and Economic Review 2: 126-69.
Brooks GR (1998) A New Psychotherapy for Traditional Men. Jossey-Bass, San Francisco, CA.

Brownhill S, Wilhelm K, Barclay L and Schmied V (2005) 'Big build': Hidden depression in men. Australian and New Zealand Journal of Psychiatry 39: 921-31.

Brownhill S, Wilhelm K, Eliovson G and Waterhouse M (2003) 'For men only'. A mental health prompt list in primary care. Australian Family Physician 32: 443-50.

Campinha-Bacote J, Yahle T and Lagenkamp M (1996) The challenge of cultural diversity for nurse educators. Journal of Continuing Education in Nursing 27: 59-64.

Ciarrochi JV (2001) Emotional competence and willingness to seek help from professional and nonprofessional sources. British Journal of Guidance and Counselling 29: 233-46.

Clemants E and Gross A (2007) 'Why Aren't We Screening?' A survey examining domestic violence screening procedures and training protocol in community mediation centers. Conflict Resolution Quarterly 24: 413-30.

Coatsworth JD, Santisteban DA, McBride CK and Szapocznik J (2001) Brief strategic family therapy versus community control: engagement, retention, and an exploration of the moderating role of adolescent symptom severity. Family Process 40: 313-32.

Commonwealth of Australia (1975) Family Law Act 1975 (incorporating the amendments made by the Family Law Amendment [Shared Parental Responsibility] Act 2006). Australian Government Publishing Services, Canberra. Available at: http://www.austlii.edu.au/au//legis/cth/consol_act/ fla1975114/ (accessed 08 February 2008).

Community Services \& Health Industry Skills Council (2007) Family Counselling, Family Dispute Resolution and Children's Contact Services: National Competency Framework. Available at: http:// www.cshisc.com.au/load_page.asp?ID=75 (accessed on 23 August 2007).

Connors GJ, Carroll KM, DiClemente CC and Longabaugh R (1997) The therapeutic alliance and its relationship to alcoholism treatment participation and outcome. Journal of Consulting and Clinical Psychology 65: 588-98.

Cross S E and Madson L (1997) Elaboration of models of the self: Reply to Baumeister and Sommer (1997) and Martin and Ruble (1997). Psychological Bulletin 122: 51-5.

Dearing RL, Barrick C, Dermen KH and Walitzer KS (2005) Indicators of client engagement: Influences on alcohol treatment satisfaction and outcomes. Psychology of Addictive Behaviors 19: 71-8. 
Department of Foreign Affairs and Trade (1995) Australian Treaty Series 1991 No 4. Available at: http://www.austlii.edu.au/au/other/dfat/treaties/19 91/4.html (accessed 3 September 2007).

Emery RE, Sbarra D and Grover T (2005) Divorce mediation: Research and reflections. Family Court Review 43: 22-37.

Family Law Act 1975, see Commonwealth of Australia.

Field R (2004) A feminist model of mediation that centralises the role of lawyers as advocates for participants who are victims of domestic violence. Australian Feminist Law Journal 20: 65-91.

Fletcher RJ (2004) Bringing Fathers in Handbook: How to Engage with Men for the Benefit of Everyone in the Family. University of Newcastle, Newcastle, New South Wales.

Foster RJ Chudleigh AS Lenton R and Gibson PS (2005). Fathers and the separation pathway: The family court of Australia in dialogue with men's groups. Journal of Family Studies 11: 187-195.

Galdas PM, Cheater F and Marshall P (2005) Men and health help-seeking behaviour: Literature review. Journal of Advanced Nursing 49: 616-23.

Gilligan C (1977) In a different voice: Women's conceptions of self and morality. Harvard Educational Review 47: 481-517.

Halpern JJ and Parks JM (1996) Vive la difference: Differences between males and females in process and outcomes in a low-conflict negotiation. International Journal of Conflict Management 7: 45-70.

Hand K (2006) Mothers' accounts of work and family decision-making in couple families. Family Matters 75: 70-6.

Heesacker M and Bradley MM (1997) Beyond feelings: Psychotherapy and emotion. The Counselling Psychologist 25: 201-19.

Heesacker M. Wester SR Vogel DL Wentzel JT MejiaMillan CM and Goodholm CRJ (1999) Genderbased emotional stereotyping. Journal of Counselling Psychology 46: 483-495.

Hewitt B Western M and Baxter J (2006) Who decides? The social characteristics of who initiates marital separation. Journal of Marriage and Family 68: 1165-77.

Hewlett B (2007) Accessing the parental mind through the heart: A case study in child-inclusive mediation, Journal of Family Studies 13: 94-103.

Holmes S (2006) Becoming 'the best possible' family counsellor or family mediator: What expertise research has to say. Journal of Family Studies 12: 113-22.

Horvath AO and Greenberg LS (1989) Development and validation of the Working Alliance Inventory. Journal of Counselling Psychology 36: 223-33.

Jackson AK (2007) Cultural competence in health visiting practice: A baseline survey. Community Practitioner 80: 17-22.

Jones TS and Bodkter A (2001) Mediating with heart in mind: Addressing emotion in mediation practice. Negotiation Journal 17: 217-44.

Katz E (2007) A family therapy perspective on mediation. Family Process 46: 93-107.

Kelly JB (2007) Children's living arrangements following separation and divorce: Insights from empirical and clinical research. Family Process 46: 35-52.

Keys Young (1996) Research/Evaluation of Family Mediation Practice and the Issue of Violence: Final Report. Attorney-General's Department, Canberra.

Kirkwood D (2006) Family law dispute resolution: The implications for victims of violence. DVIRC Quarterly 16-24.

Kumas-Tan Z, Beagan B, Loppie C, MacLeod A and Frank B (2007) Measures of cultural competence: Examining hidden assumptions. Academic Medicine 82: $548-57$.

Lamb ME (ed) (2004) The role of the father in child development, 4th Edn, Wiley, New York.

Lamb ME, Sternberg KJ and Thompson RA (1997) The effects of divorce and custody arrangements on children's behavior, development and adjustment. Family and Conciliation Courts Review 35: 393-404.

Levant RF (1998). Desperately seeking language: understanding, assessing, and treating normative male alexithymia, in Pollack W S and Levant R F (eds) New Psychotherapy for Men, pp 35-56, Wiley, New York.

Liu WM (2005) The study of men and masculinity as an important multicultural competency consideration. Journal of Clinical Psychology 61: 685-97.

Martin D, Garske J and Davis M (2000) Relation of the Therapeutic Alliance with outcome and other variables: A meta-analytic review. Journal of Consulting and Clinical Psychology 68: 438-50.

McBride B and Rane T (1998) Parenting alliance as a predictor of father involvement: An exploratory study. Family Relations: Journal of Applied Family and Child Studies 47: 239-36.

McCarthy J and Holliday EL (2004) Help-Seeking and counselling within a traditional male gender role: An examination from a multicultural perspective. Journal of Counselling and Development 82: 25-32.

McIntosh J and Deacon-Wood HB (2003) Group interventions for separated parents in entrenched 
conflict: An exploration of evidence-based frameworks. Journal of Family Studies 9: 187-99.

McIntosh JE and Long CM (2006) Children Beyond Dispute: A Prospective Study of Outcomes from Child Focused and Child Inclusive Post-separation Family Dispute Resolution. Final Report. Australian Government Attorney General's Department, Canberra.

McIntosh JE and Moloney L (2006) Dialogues with Separated Parents: Child Focused Dispute Resolution. COMET, La Trobe University, Melbourne

Moloney L (2006) Child-Sensitive practices in highconflict parenting disputes: A 30-year road to serious reform. Journal of Family Studies 12: 37-56.

Moloney L and McIntosh JE (2004) Child responsive practices in Australian family law. Journal of Family Studies 10: 71-86.

Moynihan C (1998) Theories of masculinity. British Medical Journal 317:1072-75.

National Health and Medical Research Council (NHMRC) (2005) Increasing Cultural Competency for Healthier Living and Environments: Discussion Paper 24. NHMRC, Canberra.

National Health and Medical Research Council (NHMRC) (2006) Cultural Competency in Health: A Guide for Policy, Partnerships and Participation. NHMRC, Canberra.

Pines AM, Gat H and Tal Y (2002) Gender differences in content and style of argument between couples during divorce mediation. Conflict Resolution Quarterly 20: 23-50.

Reimann JOF, Talavera GA, Salmon M, Nunez JA and Velasquez RJ (2004) Cultural competence among physicians treating Mexican Americans who have diabetes: A structural model. Social Science and Medicine 59: 2195-205.

Rickwood DJ and Braithwaite VA (1994) Socialpsychological factors affecting help-seeking for emotional problems. Social Science and Medicine 39: 563-72.

Robertson JM and Fitzgerald LF (1992) Overcoming the Masculine Mystique: Preferences for alternative forms of assistance among men who avoid counselling. Journal of Counselling Psychology 39: 240-46.

Rodolfa E, Bent R, Eisman E, Nelson P, Rehm L and Ritchie P (2005) A cube model for competency development: Implications for psychology educators and regulators. Professional PsychologyResearch and Practice 36: 347-54.

Russell G, Barclay L, Edgecombe G, Donovan J, Habib G and Callaghan H (1999) Fitting Fathers into Families: Men and the Fatherhood Role in Contemporary Australia. Commonwealth Depart- ment of Family and Community Services, Canberra.

Scott KL and Crooks CV (2004) Effecting change in maltreating fathers: Critical principles for intervention planning. Clinical Psychology: Science \& Practice 11: 95-111.

Shay JJ and Maltas CP (1998) Reluctant men in couple therapy: Corralling the Marlboro Man, in Pollack WS and Levant RF (eds) New Psychotherapy for Men, pp 97-126, Wiley, New York.

Smyth BM and Moloney L (2003) Therapeutic Divorce Mediation: Strengths, limitations, and future directions. Journal of Family Studies 9: 161-186.

Sourdin T, Fisher T and Moloney L (2004) Towards Quality Standards for Family Dispute Practitioners Research Report. Available at: http://www.ag.gov .au/www/agd/agd.nsf/Page/Publications (accessed on 3 September 2007).

Stroebe M, Stroebe W and Schut H (2001) Gender differences in adjustment to bereavement: An empirical and theoretical review. Review of General Psychology 5: 62-83.

Sue S (1998) In search of cultural competence in psychotherapy and counselling. American Psychologist 53: 440-8.

Symonds BD (1999) The Measurement of Alliance in Short Term Couples Therapy. Unpublished doctoral thesis. Simon Fraser University, Burnaby, BC, Canada.

Symonds D and Horvath AO (2004) Optimizing the alliance in couple therapy. Family Process 43: 443-55.

Vogel DL, Wester SR, Heesacker M and Madon S (2003) Confirming gender stereotypes: a social role perspective. Sex Roles 48: 11-12.

Wadsby M and Svedin CG (1992) Divorce: Different experiences of men and women. Family Practice 9: 451-60.

Weissman S and Cohen RS (1985) The parenting alliance and adolescence. Adolescent Psychiatry 12: 24-45.

Wolcott I and Hughes J (1999) Towards Understanding the Reasons for Divorce. Working Paper 20.

Australian Institute of Family Studies, Melbourne, Victoria.

Wong YJ and Rochlen AB (2005) Demystifying men's emotional behavior: New directions and implications for counselling and research. Psychology of Men and Masculinity 6: 62-72.

Zaher S (1998) The feminisation of family mediation. Dispute Resolution Journal 53: 36-44. 